\title{
Liver Parenchyma Regeneration in Connection with Extended Surgical Procedure - Experiment on Large Animal
}

\author{
Vaclav Liska et al. ${ }^{1 *}$ \\ 1Department of Surgery \\ Teaching Hospital and Medical School Pilsen, Charles University Prague, \\ Czech Republic
}

\section{Introduction}

Liver surgery underwent enormous evolution after development and introduction of new technical skills in surgical praxis. Nevertheless many patients with primary or secondary liver malignancies are not indicated to radical surgical therapy that could reach complete remission of malignant disease because the frontiers of liver surgery are limited today by the functional reserves of remnant parenchyma. The main argument to non surgical treatment is increased risk of acute liver failure after extended liver resection, where retained liver parenchyma is to small to sustain the liver functions (Abdalla, 2001). Portal vein embolization (PVE) can multiply the future liver remnant volume (FLRV) in spite of affection of only one of liver lobes by malignant diseases (Makuuchi, 1984, Makuuchi, 1990, Harada, 1997). This procedure was performed firstly in 1984 by Makuuchi (Abdalla, 2001, Makuuchi, 1984, Makuuchi, 1990). PVE of portal branch of with malignancy afflicted liver lobe initiates compensatory hypertrophy of contralateral non-occluded lobe. The occluded lobe underlies atrophy. The compensatory hypertrophy is supposed to be stimulated by increased flow of portal blood, that contains hepatotrophic substances (Kusaka, 2004, Azoulay, 2000). Liver resection after PVE is performed only in 63-96\% of patients (Kokudo, 200, Stefano, 2005, Lagasse, 2000). The main reason for this resolution is unsuccessful hypertrophy of FLRV or progression of malignancy. Liver resection after PVE is performed only in 63-96\% of patients (Azoulay, 200, Kokudo, 2001, Stefano, 2005). The main reason for this resolution are unsuccessful hypertrophy of FLRV or progression of malignancy.

\footnotetext{
${ }^{*}$ Vladislav Treska1 ${ }^{1}$,Hynek Mirka ${ }^{2}$, Ondrej Vycital ${ }^{1}$, Jan Bruha ${ }^{1}$, Pavel Pitule ${ }^{1}$, Jana Kopalova ${ }^{1}$, Tomas Skalicky ${ }^{1}$, Alan Sutnar ${ }^{1}$, Jan Benes ${ }^{3}$, Jiri Kobr ${ }^{4}$, Alena Chlumska ${ }^{5}$, Jaroslav Racek ${ }^{6}$ and Ladislav Trefil ${ }^{6}$

${ }^{1}$ Department of Surgery,

${ }^{2}$ Department of Radiology,

${ }^{3}$ Department of Anaesthesiology and Resuscitation,

${ }^{4}$ Department of Pediatrics,

Institute of Pathology,

${ }^{6}$ Institute of Biochemistry and Haemathology,

Teaching Hospital and Medical School Pilsen, Charles University Prague, Czech Republic
} 
The proper regeneration of liver parenchyma depends on proliferation of parenchymal and non-parenchymal liver cells. The importance of stem cells or liver oval cells is still under discussion and this mechanism provokes many questions (Lagasse, 2000, Petersen, 1999, Vassilopoulos, 2003). After partial hepatectomy or portal vein ligation increase serum levels of Tumour necrosis factor alpha (TNF-a) and Interleukin-6 (IL-6), which were demonstrated to be involved in priming of hepatocytes and trigger them from G0 to G1 cell cycle phase(Cornell, 1990). These cytokines induce gene activation, which are responsible for G1 phase. Both pleiotrophic cytokines are secreted by non-parenchymal liver cells (mostly Kupffer cells) (Fausto, 2000, Fausto, 2005). TNF-a is superior to IL-6 and stimulates increased secretion of IL-6. In hepatectomized regenerating liver, it is known that this signaling pathway follows the sequence TNF- $\alpha \rightarrow$ TNFR- $\rightarrow$ NFKB $\rightarrow$ IL-6 $\rightarrow$ STAT3 (Michalopoulos, 1997). The proliferation of primed hepatocytes is regulated positively by Hepatocyte growth factor (HGF), Epidermal growth factor (EGF), Insulin-like growth factor (IGF), Transforming growth factor-alpha (TGF-a), etc. The termination of proliferation and stimulation of hepatocyte to differentiation, final remodelation of liver tissue and production of extracellular matrix is controled by Transforming growth factor-beta (TGF- $\beta$ ) (Fukuhara, 2003, Mangnall, 2003, Zimmermann, 2004). TGF- $\beta 1$ plays the most important role in starting the remodelling of the extracellular matrix and restoration of the original structure of the liver parenchyma. TGF- $\beta 1$ inhibits DNA synthesis and plays a pivotal role in the down-regulation of liver regeneration as has been demonstrated in toxic models of liver regeneration (Armendariz-Borunda, 1993, Armendariz-Borunda, 1997). TGF- $\beta 1$ also down-regulates the production of the Hepatocyte growth factor that sustains hepatocyte proliferation (Bustos, 2000). Increased expression of TGF- $\beta 1$ prevents uncontrolled growth during liver regeneration by the regulation of hepatocyte transition from the G1 to the $S$ phase of the cell cycle (Kusaka, 2006, Oe, 2004). TGF- $\beta 1$ helps maintain the differentiation of hepatocytes and non-parenchymal liver cells. The proposed HGF/ TGF- $\beta 1$ ratio could reflect the proliferation/differentiation status of hepatocytes (Lilja, 1999). Increased expression of TGF- $\beta 1$ was also shown to be a crucial factor for the progression of hepatic fibrosis (Friedman, 2008). This could be explained by increased or prolonged production of the liver extracellular matrix (Viebahn, 2008).

The replication of hepatocytes culminates on 7th days (14per cent of hepatocytes) and the return to quiscent status was observed on 12th day after PVE in swine experimental model (Coelho, 2007, Duncan, 1999). The differencies between PVE and PVL (portal vein ligation) were not proved as statistical significant for reached FLRV (Broering, 2002).

Multipotent mesenchymal stromal cells (MSC) are a fraction of the adult bone marrow stem cell compartment. They contain a subpopulation of mesenchymal stem cells that can differentiate into mesenchymal adult tissues under specified conditions. Differentiation into adipocytes, chondrocytes, osteoblasts and myocytes has been demonstrated in vitro and in vivo (Barry, 2003). Whether and how bone marrow-derived stem cells, and MSC in particular, can contribute to liver regeneration is not entirely clear. Initital reports outlined that bone marrow-derived (stem) cells can transdifferentiate into liver cells or their progenitors after bone marrow transplantation (Jiang, 2002, Lagasse, 2000, Petersen, 1999, Ringe, 2002). Later investigations clarified and complemented these observations, outlining that bone marrow cells can also fuse with resident liver cells (Vassilopoulos, 2003, Wang, 2003). In addition to direct cellular effects, transplanted bone marrow cells can also contribute to liver 
regeneration by bystander effects, such as the provision of a beneficial proliferative cytokine milieu or antiapoptotic effects (Aldeguer, 2002, Dahlke, 2004, Liska, 2009).

The aim of presented studies was to influence regeneration of liver parenchyma after portal vein embolization/ligation by exogenous cytokines, growth factors and monoclonal antibodies against growth factors with inhibitory funcions or syngeneic Multipotent Mesenchymal Stromal Cells.

\section{Methods}

\subsection{Surgical procedure}

All described procedures were prepared and performed after by law of Czech Republic, which is compatible with legislature of European Union. The experimental animal was piglet. The experimental porcine model was established to be as much compatible as possible with PVE/PVL in human medicine.

There were no statistical differencies in weight and age of the piglets undergoing portal vein ligation. The animals were housed under same conditions. In this study there were included 9 piglets in control group, 9 piglets in TNF-a group, 8 piglets in IL- 6 group, 6 piglets in MSC group and 7 piglets in MAB TGF- $\beta 1$ group.

The piglets were premedicated intramuscularly with atropine 1,5 $\mathrm{mg}$ and azaperon 1,0 $\mathrm{mg} / \mathrm{kg}$. The anesthesia was administered continually through central venous catheter in whole average doses: azaperon 1,0 mg/ kg/hour, thiopental $10 \mathrm{mg} / \mathrm{kg} /$ hour, ketamin 5-10 $\mathrm{mg} / \mathrm{kg} /$ hour and fentanyl $1-2 \mathrm{ug} / \mathrm{kg} /$ hour. The muscle relaxation was provided by bolus administration of pancuronium $0,1-0,2 \mathrm{mg} / \mathrm{kg}$ at the begin of surgery. Animals were intubated and mechanically ventilated during surgical procedure. The monitoring of electrocardiogram, oxygen saturation and central venous pressure was performed. The surgical procedure was performed under aseptic and antiseptic conditions. The antibiotic prophylaxis was administered in total dosis of 1,2 $\mathrm{g}$ amoxicillin with clavulanic acid divided into two doses (before surgery and two hours later).

The middle laparotomy was performed. The portal vein branches for caudate, right lateral and right medial lobes (50-60 per cent of supposed liver parenchyma) were prepared and ligated without injury or ligation of hepatic artery branches. The blood flow in hepatic artery branches and occlusion of portal vein branches were controled by Doppler ultrasonography (Medison Sonoace 9900, linear probe with frequency 7,5 MHz, Fig.1). The borders between atrophic and hypertrophic liver lobes were marked by titanium staples to simplify the postoperative ultrasonography.

The recombinant porcine TNF-a in amount 5 $\mathrm{gg} / \mathrm{kilos}$ (rpTNF- $\alpha$, ProSpec TechnoGene, Israel, 9 piglets from TNF-a group), the recombinant porcine IL-6 in amount 0,5 $\mu \mathrm{g} / \mathrm{kg}$ (rpIL6, ProSpec TechnoGene, Israel, 8 piglets from Il-6 group), MSC (autologous bone marrow stem cells cultured in expansion medium (low glucose DMEM with GlutaMAX, without pyruvate, Biochrom) supplemented with $10 \%$ fetal bovine serum (FBS, Biochrom), 1\% penicillin/streptomycin and 1\% glutamine. After 24, 48 and 72 hours, non-adherent cells were removed by changing the culture medium. Adherent cells were then trypsinized $(0.5 \%$ trypsin-EDTA), harvested and re-plated into new flasks, each time, when cell confluency reached $60 \%$ to $80 \%$. To histologically identify transfused MSC within the recipient liver, 
cultured MSC were labeled with 5-bromo-2-deoxyuridine (BrdU) 60 hours before cell application. 6 piglets, the amount of applied stem cells: 8.75, 14.0, 17.0, 17.5, 43.0 and $61.0 \mathrm{x}$ $10^{6}$ MSC respectively) or physiological solution (9 piglets from control group) were applied into non-occluded portal vein branches (Liska, 2012, Liska, 2009, Liska, 2009, Teoh 2006).

The laparotomy was closed in anatomical layers. At the end of operation the port-a-cath was introduced into the superior caval vein. The animals were extubated and monitored each day for the next fourteen days with a particular emphasis on the clinical examination (attention to wound healing, infection of the port-a-cath and function of the gastrointestinal system) to diagnose possible surgical complications. The postoperative analgezia was provided by intramuscular application of small dosis of Azaperon (10mg).

Administration of MAB TGF- $\beta 1$ was performed into central venous catheter 24 hours after ligation (7 piglets, 40 $\mathrm{gg} / \mathrm{kg}$ of body weight) ( Armendariz-Borunda , 1993, Deneme, 2006, Liska, 2012).

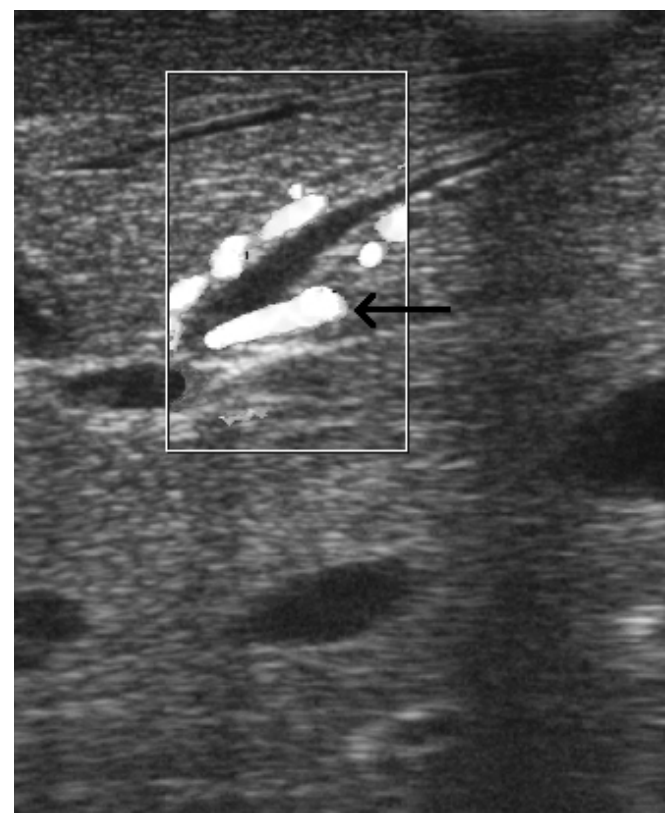

Fig. 1. Doppler ultrasonography of liver parenchyma with occluded portal vein branch and non occluded branch of hepatic artery (arrow).

\subsection{Biochemistry and immunoanalysis}

The blood samples were collected from central vein catheter at 1 . before operation, 2. after ligation of the last portal branch, 3. at the end of operation, 4.2 hours after operation, 5. 1th postoperative day (p.d.), 6. 3rd p.d., 7. 7th p.d., 8. 10th p.d., 9. 14th p.d.

The following biochemical parametres were estimated by biochemical analysator Olympus 2700: bilirubin, urea, creatinine, alkaline phosphatase (ALP), gamaglutamyltransferase 
(GGT), cholinesterase (CHE), aspartylaminotransferase (AST), alanine aminotransferase (ALT) and albumin.

Serum level of C-reactive protein (CRP), studied cytokines (TNF-a and IL-6) and growth factors (TGF- $\beta 1$, IGF) were meassured by enzyme-linked immunosorbent assay (ELISA) by Auto-EIA II Analyzer (Lasystems Oy Helsinki, Finland).

\subsection{Ultrasonography}

The ultrasonographic controls were undertaken immediately after operation and on 3rd, 7th, 10th and 14th postoperative day (ultrasound machine Medison Sonoace 9900, convex probe with frequency 3,5 MHz). The diameters of atrophic and hypertrophic (functional liver remnant volume) lobes were meassured in B-modus in all three basic planes (axial, sagittal and coronary). The volume of lobes is counted by using standard ultrasonographic formula, which is used also in human medicine: axial $x$ sagittal $x$ coronary / 2 (Liska, 2009).

\subsection{Histology}

The experiment was finished on 14th day by sacrifying of animals under general anaestesia with concentrated solution of potassium chloride administered into central venous catheter.

The histological material from atrophic and hypertrophic parenchyma was examined after staining with hematoxyline-eosine, periodic acid-Schiff (PAS) staining and PAS staining after digestion of preparations with diastase. The proliferation activity was examined using antibody Ki67 (MIB 1 MW, 1:1000 DakoCytomation). We concentrated especially at the measurement of lobulus length, binucleated hepatocyte, length of hepatocytes. The amount of binucleated hepatocytes were measured in 20 microscopic fields by an eyepiece micrometer (Olympus). The size of the hepatocytes and the length of the lobuli were examined twice using the eyepiece micrometer (Olympus).

\subsection{Statistical analysis}

Statistical analysis was performered by sofware CRAN 2.4.0 and STATISTICA 98 Edition. The meassured parameters (biochemistry, immunoanalysis, ultrasonography) were described by basic statistical variables - mean, median, standard deviation, minimum, maximum and quartile extent. The statistical data were processed graphicaly into Box and Whisker plot diagrams. The comparison of distribution of studied parameters in groups was counted by distribution-free test (Wilcoxon). The Spearman Rank Correlation Coefficient was used because of non-Gausian distribution of parameters values. The whole development of studied parameters in time was compared between groups by parametric test ANOVA.

\section{Results}

\subsection{Functional liver remnant volume}

To assess the overall functional effect of MSC infusions, rpTNF- $\alpha$ group, rpIL-6 and MAB TGF- $\beta 1$ after partial portal vein ligation in the porcine model, the volume of the occluded and non-occluded liver lobes was analyzed by ultrasonography. Repeated ultrasonographic 
assessments were carried out on p.d. $0,3,7,10$ and 14. The volumes of both the ligated right, and the non-ligated left liver lobes were computed by a standard three-dimensional ultrasonographic approach and were confirmed by physical examination during necropsy on day 14. The volume of the hypertrophic lobe increased more rapidly after MSC application in the treatment group when compared to the control group (Figure 2). The control group did not show any change in the volume of the hypertrophic liver lobes within the first three days after surgery. The growth acceleration of the hypertrophic liver lobes in the MSC group was at its maximum between the $3 \mathrm{rd}$ and 7 th $\mathrm{p} . \mathrm{d} .(\mathrm{p}<0.05$ versus control). However, this stimulating effect slowed down during the second week and there was no statistically significant difference in the size of the hypertrophic liver lobes on day 14 . However, the average volume of the non-occluded liver lobe was increased by $30 \%$ in the MSC group in contrast to the control group at the end of the experiment (Fig. 2),( Liska, 2009).

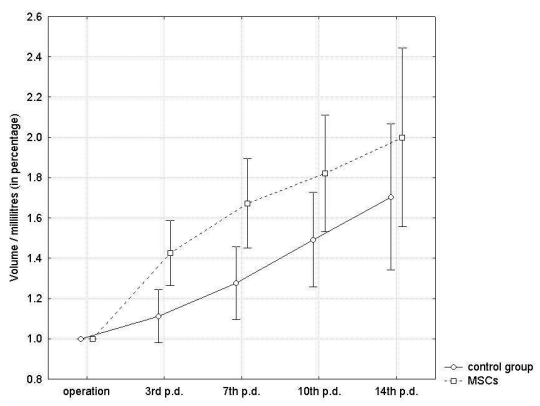

Fig. 2. Volumes of the non-ligated liver lobes are depicted for the control and the MSCtreated group. Liver volume was assessed by 3D ultrasonographic measurements.

In case of TNF-a group the absolute volume of hypertrophic lobes increased after application of TNF-a more rapidly wheareas the control group has no changes in hypertrophic liver lobes volumes in first three days. The acceleration of growth of hypertrophic liver lobes in TNF-a group was maximal on 7th p.d. in comparisson with control group ( $p<0.05)$, nevertheless this stimulating effect was lost on the 14th p.d. and the differencies were not statistically significant (Fig.3) ,( Liska, 2012).

The absolute volume of hypertrophic lobes grew more rapidly after application of MAB TGF- $\beta 1$, whereas the control group had a slow but continual growth in the hypertrophic liver lobes during the whole follow-up period. The augmentation of growth of the hypertrophic lobes was maximal between the $3^{\text {rd }}$ and $7^{\text {th }}$ postoperative days in comparison with the control group $(p<0.05)$. Nevertheless this growth accelerating effect was lost during the next ultrasonographic controls, and on the $14^{\text {th }}$ postoperative day there were no statistically significant differences (Fig. 4),( Liska, 2012).

IL-6 group demonstrated growth of volume of hypertrophic lobes more rapidly after application of studied cytokine wheareas the control group has slow start of growth in hypertrophic liver lobes in first three days. The acceleration of growth of hypertrophic liver lobes in IL-6 group was maximal on 7 th p.d. in comparisson with control group $(p<0.05)$, nevertheless this stimulating effect was also lost during the follow up period and on 14th p.d there were no statistically significant differencies as at other experimental groups (Fig.5), (Liska, 2009). 


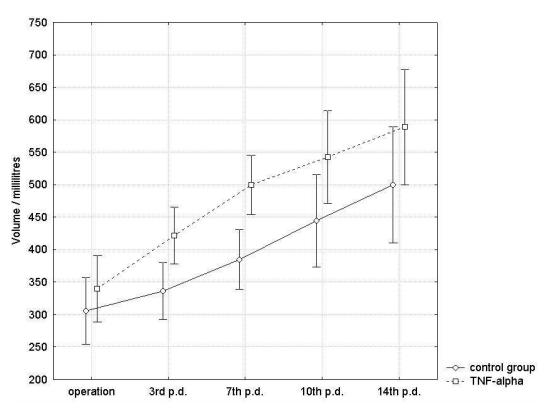

Fig. 3. Comparison of liver hypetrophy between control group and TNF-a group.

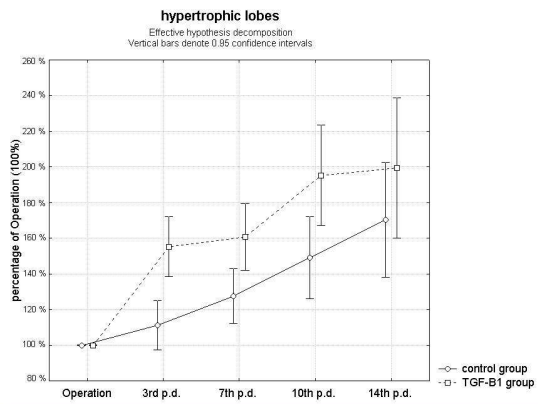

Fig. 4. Comparison of the growth of hypertrophic liver lobes between TGF- $\beta 1$ and control groups.

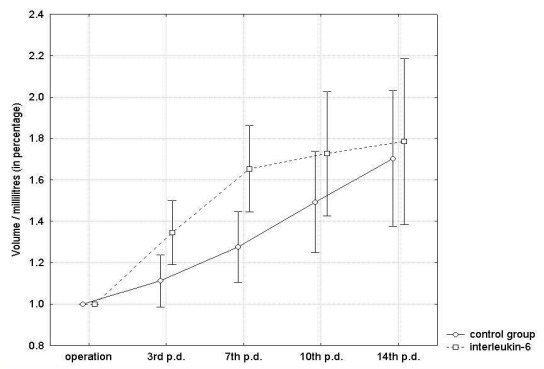

Fig. 5. Comparison of hypertrophic liver lobes growth between IL-6 group and control group.

\subsection{Biochemistry}

To outline the functional liver capacity after the infusion of MSC and to understand possible systemic side effects, biochemical parameters, as well as cytokine and growth factor levels were analyzed in sera of both animal groups during and after the intervention. All parameters were measured on a clinical analyzer before and during the procedure, as well as on p.d. 1, 3, 7, 10 and 14. Serum levels of AST and ALT increased after portal vein ligation, whereas serum cholestatic markers bilirubin, ALP and GGT remained stable. Synthetic liver function was unchanged with normal levels of CHE (Fig. 6). There was no difference 

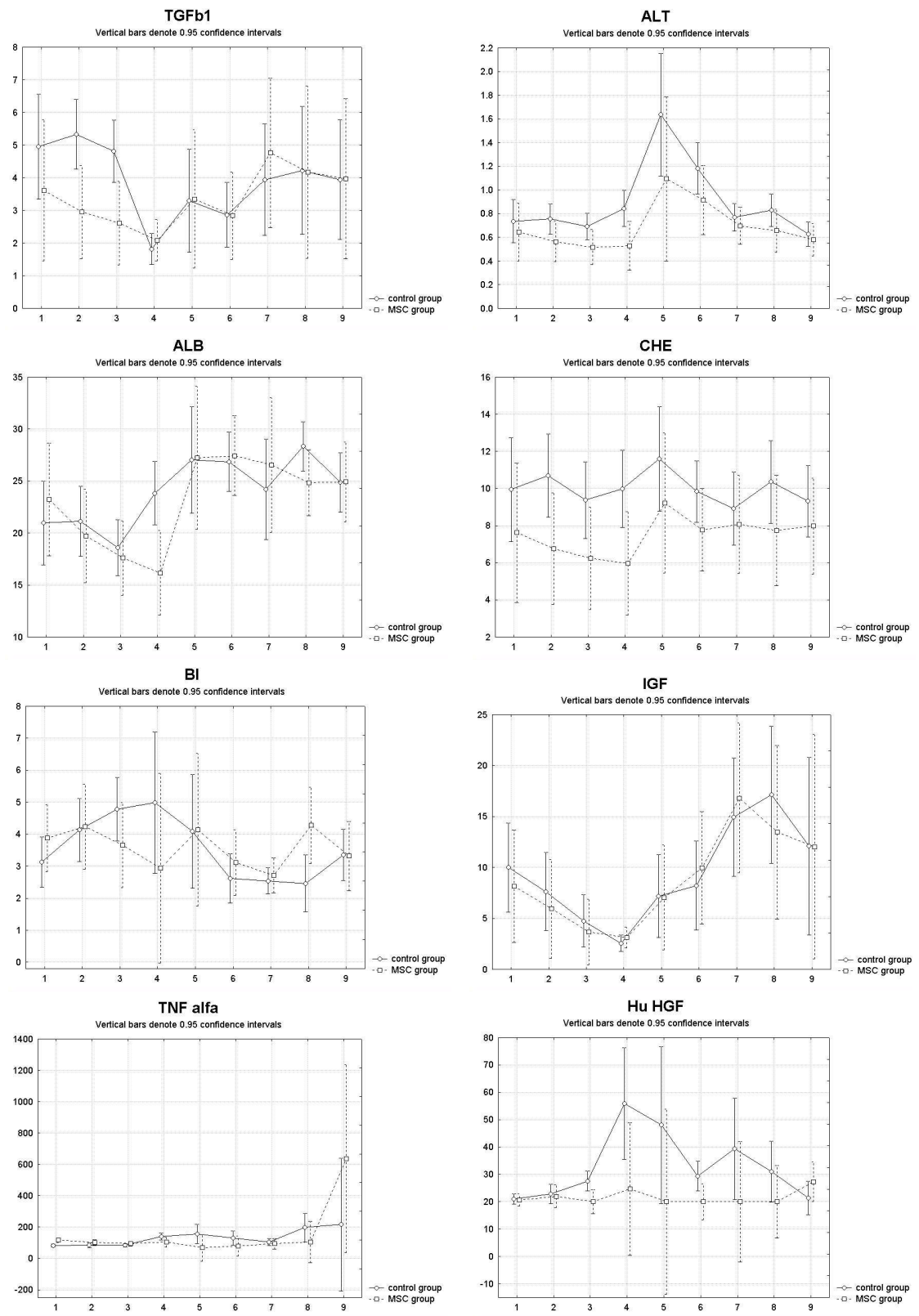

Fig. 6. Comparison of serum biochemistry during the postoperative period between MSC and control group: Blood was drawn from piglets before and during the procedure, as well as on postoperative days 1,3, 7, 10 and 14. Liver function tests and other biochemical markers were measured on a clinical analyzer and are depicted as mean $+/$ - standard 
deviation. $(\mathrm{ALB}=$ serum albumin, $\mathrm{ALT}=$ alanine aminotransferase, $\mathrm{CHE}=$ cholinesterase, $\mathrm{BI}=$ serum bilirubin and growth factors TGFb1, IGF and HGF).

between the MSC-treated and the control group regarding these markers. Serum CRP levels were elevated to the same extent in all animals during the postoperative period. Kidney function was stable in all piglets with physiological levels of creatinine and urea (Fig.6). Overall, all treated animals of both groups tolerated the treatment well with neither apparent differences in the clinical course or the biochemistry markers assessed. To describe the regenerative micromilieu within recipient livers, the secretion of growth factors HGF, IGF, TGF $\beta 1$ and TNFa was analysed in sera of all animals over time. Both groups expressed the same pattern of TGFß1, IGF and TNFa in the periphery with a tendency towards decrease of TGFß1 and IGF in the early phase and stable TNFa. HGF expression was slightly higher in the control group early after the procedure. Nevertheless, there were no proved statistical differences between studied cytokines and growth factors in particular time points. Overall, the cytokine expression pattern in the periphery indicates that differences in the extent of postoperative liver hypertrophy between the groups are most likely due to micromilieu changes within defined anatomical spaces in the liver (Liska, 2009).

The serum levels of all studied biochemical and immunological parameteres compared between TNF-a and control group are presented in figure 7 and 8 . The serum levels of all studied biochemical parameters achieved no statistically signifficant differences. The other studied serum biochemical parameteres were comparable in both experimental groups and the differences did not prove any statistical significancy.
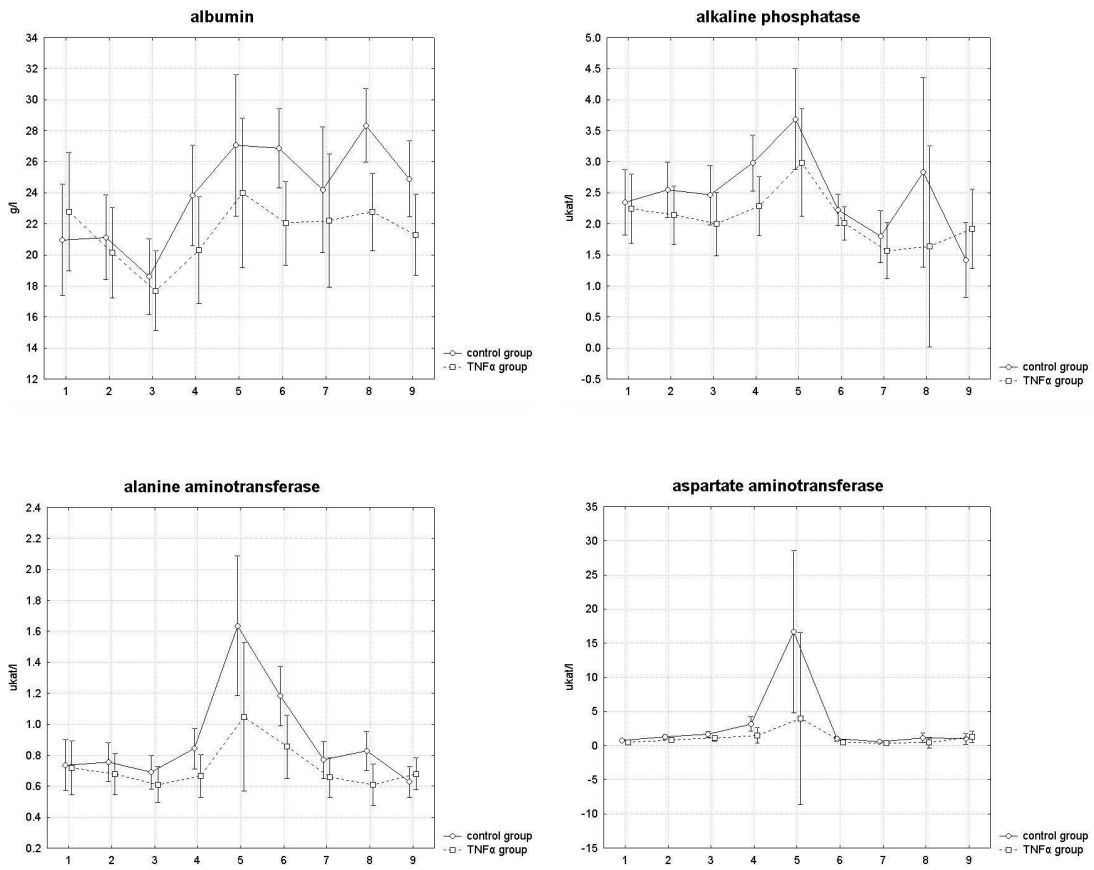

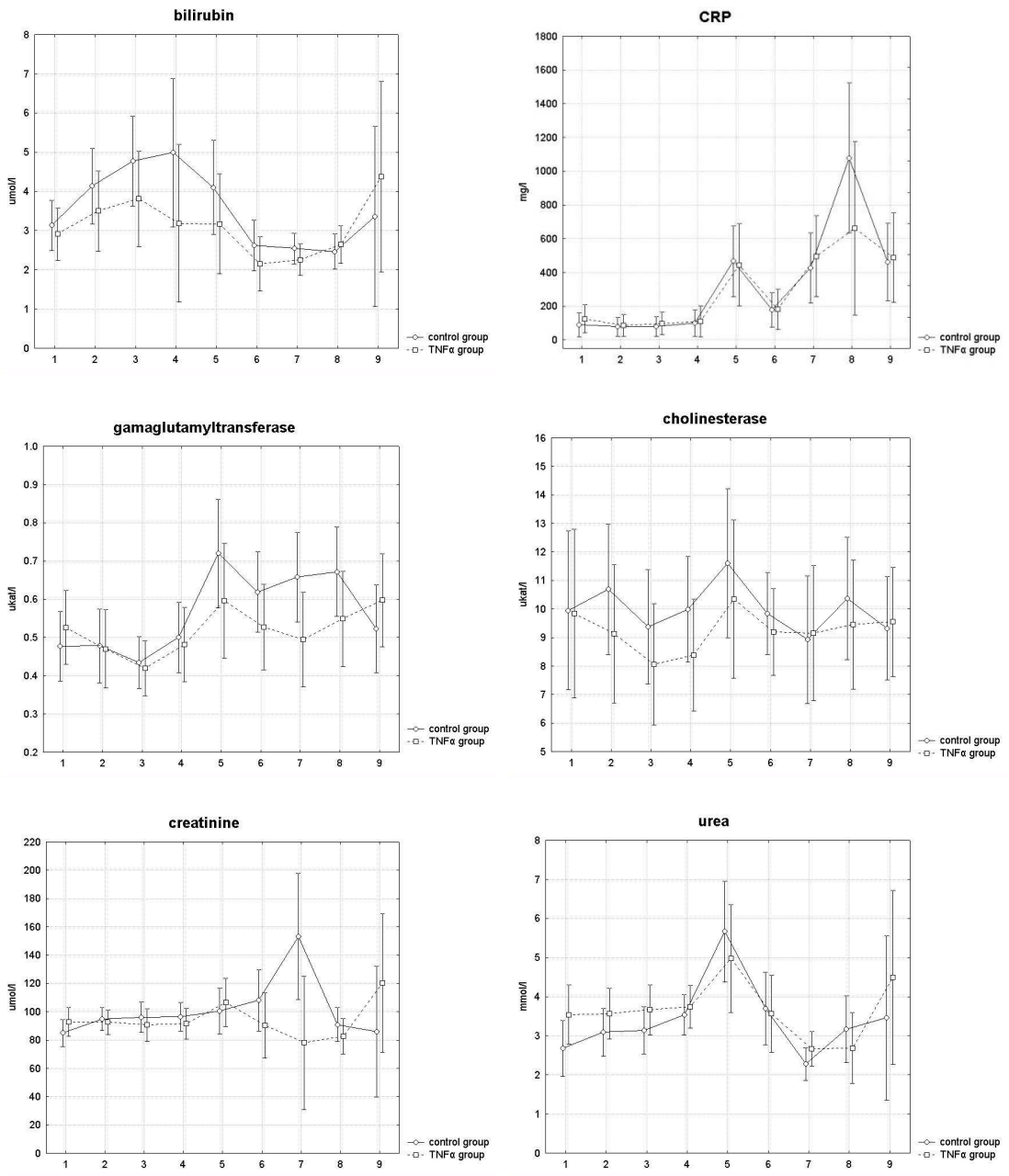

Fig. 7. Comparison of serum levels of studied biochemical parametres (albumin, alkaline phosphatase, alanine aminotransferase, aspartate aminotransferase, bilirubin, C-reactive protein, gamaglutamyltransferase, cholinesterase, creatinine and urea) between TNF- $\alpha$ and control groups during liver hypertrophy. (1) before operation, (2) after ligation of the last portal branch, (3) 30 minutes after partial portal vein ligation - application of TNF-a or physiological solution, (4) 2 hours after partial portal vein ligation, (5) $1^{\text {st }}$ postoperative day p.d., (6) $3^{\text {rd }}$ p.d., (7) $7^{\text {th }}$ p.d., (8) $10^{\text {th }}$ p.d., (9) $14^{\text {th }}$ p.d.

The serum level of TNF-a increased after application of studied cytokine but its serum level got practically normalized on first p.d. (p-value<0.05) (fig.8). The serum levels of all other studied cytokines and growth factors expressed no differences between TNF- $\alpha$ and control group. We did not distingush any serum level changes of CRP (Liska, 2012). 
In case of TGF- $\beta 1$ group the serum levels of all the studied biochemical parameters and the progression of curves are presented in figure 9. All studied serum biochemical parameters were comparable in both experimental groups and the differences shows no statistical significance between the TGF- $\beta 1$ and the control group at each timepoint (Liska, 2012).
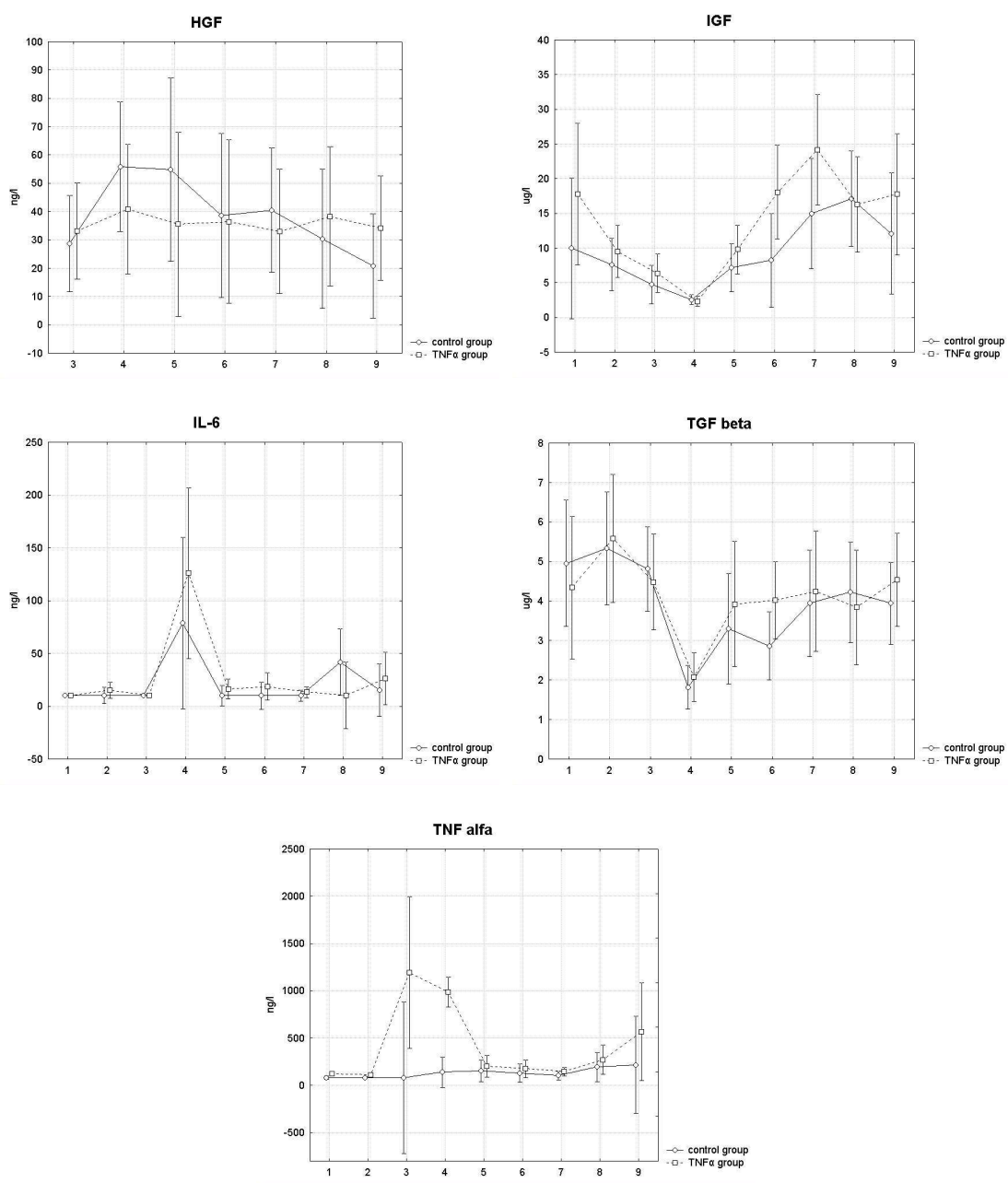

Fig. 8. Comparison of serum levels of studied cytokines and growth factors (HGF, IGF, IL-6, TGF $\beta-1$ and TNF- $\alpha$ ) between TNF- $\alpha$ and control groups during liver hypertrophy. (1) before operation, (2) after ligation of the last portal branch, (3) 30 minutes after partial portal vein ligation - application of TNF-a or physiological solution, (4) 2 hours after partial portal vein ligation, (5) $1^{\text {st }}$ postoperative day p.d., (6) $3^{\text {rd }}$ p.d., (7) $7^{\text {th }}$ p.d., (8) $10^{\text {th }}$ p.d., (9) $14^{\text {th }}$ p.d. 

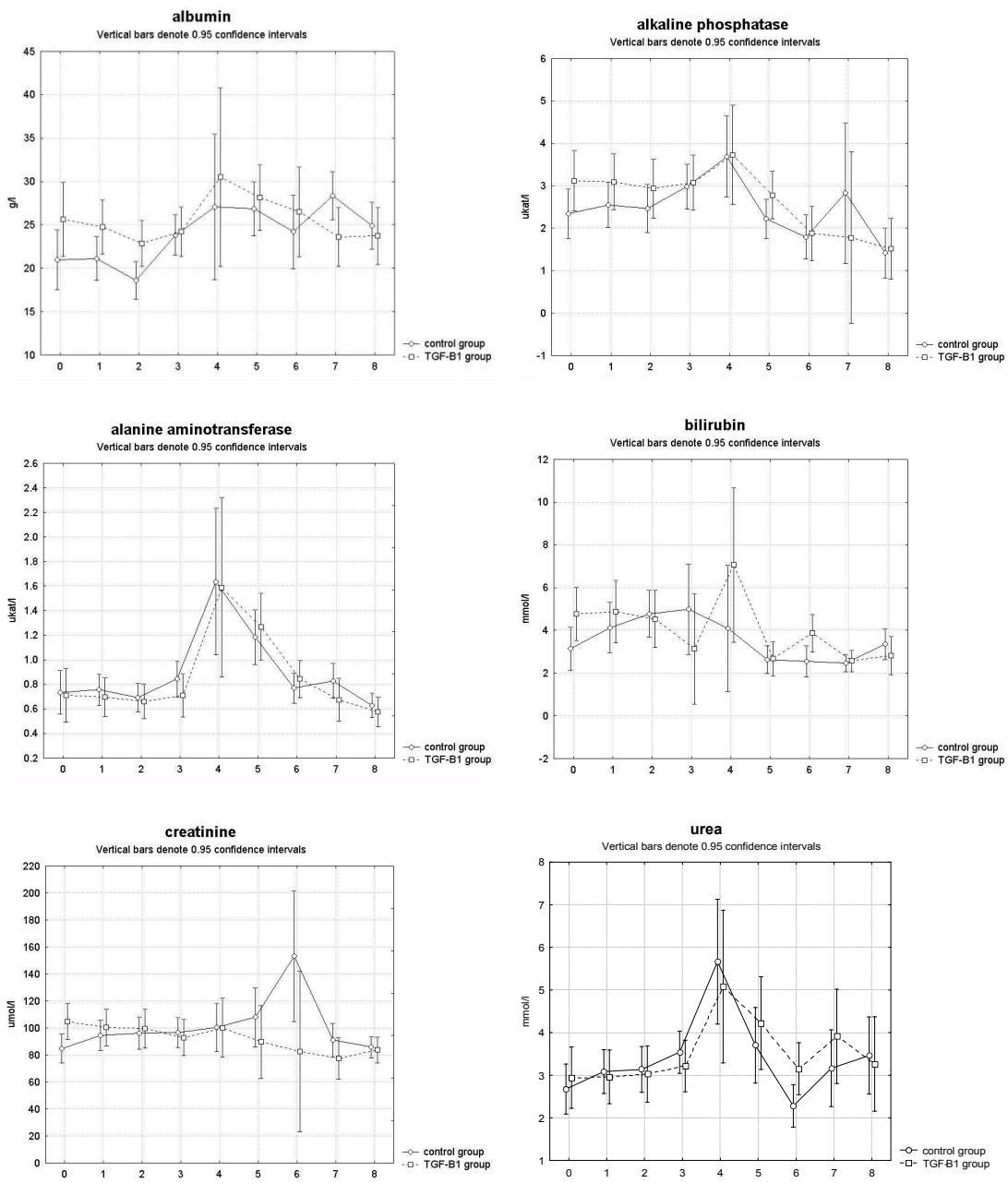

Fig. 9. Comparison of serum levels of some of the studied biochemical parameters between TGF- $\beta 1$ and control groups. (1) before operation, (2) after ligation of the last portal branch, (3) 30 minutes after partial portal vein ligation, (4) 2 hours after partial portal vein ligation, (5) $1^{\text {st }}$ postoperative day p.d. (before application of MAB TGF- $\beta 1$ or physiological solution), (6) $3^{\text {rd }}$ p.d., (7) $7^{\text {th }}$ p.d., (8) $10^{\text {th }}$ p.d., (9) $14^{\text {th }}$ p.d.

All studied serum biochemical parameters compared between IL-6 and control groups were comparable and the differences did not prove any statistical significancy in each time point (Fig. 10). The serum levels of all studied cytokines and growth factors expressed no statistically significant differences between IL-6 and control group in each time point (Fig. 11). We did not distinguish any serum level changes of CRP (Liska, 2009). 

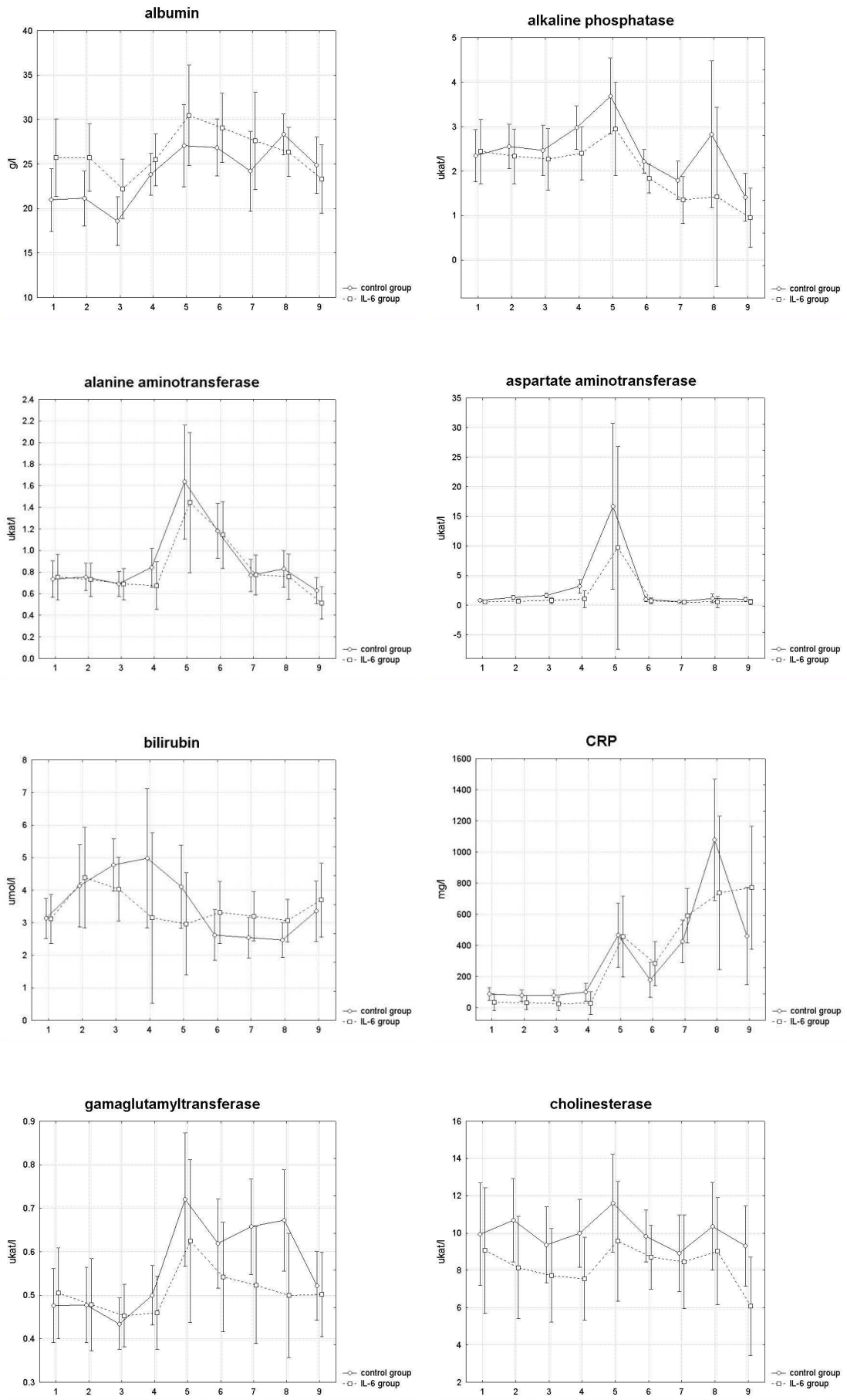

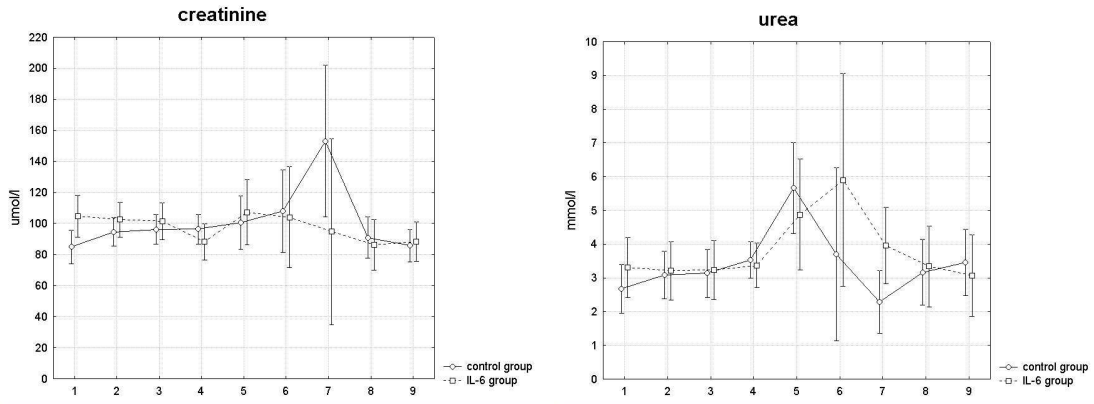

Fig. 10. Comparison of serum levels of studied biochemical parameters between IL-6 group and control group.
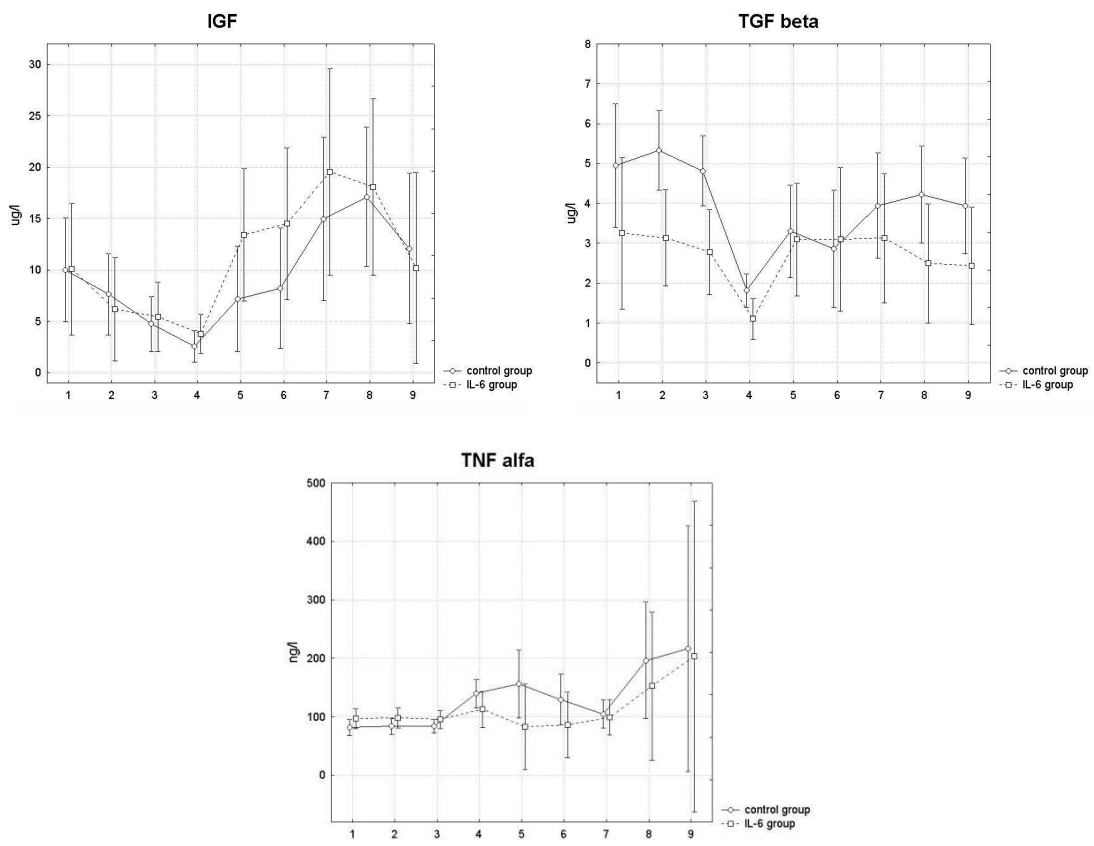

Fig. 11. Comparison of serum levels of studied cytokines and growth factors between IL-6 group and control group.

\subsection{Histology and Immunohistology}

Histological examination of liver biopsies from MSC and control groups was carried out to outline differences in the proliferative response and the composition and size of liver cells between the groups. Screening for a possible involvement of resident progenitor cells was also performed to try and identify the infused population of MSC. The analysis was performed at the time of necropsy on the $14^{\text {th }} \mathrm{p}$.d. No overall difference in the length of liver lobuli was detected between the groups on H\&E staining. However, a tendency towards 
longer lobuli was demonstrated in the MSC-treated group, potentially indicating a bystander effect of the infused MSC on the size of liver lobuli. Although lobuli length was slightly increased, the size of the individual hepatocytes did not prove to be different between the groups and the number of binucleated hepatocytes was equal in both groups. Two weeks after the intervention, the intrinsic proliferative activity was low in both groups and the Ki67 proliferative index was practically the same as in normal liver tissue.. Only solitary BrdU-stained transplanted MSC were detected within the hypertrophic liver parenchyma (Fig. 12).

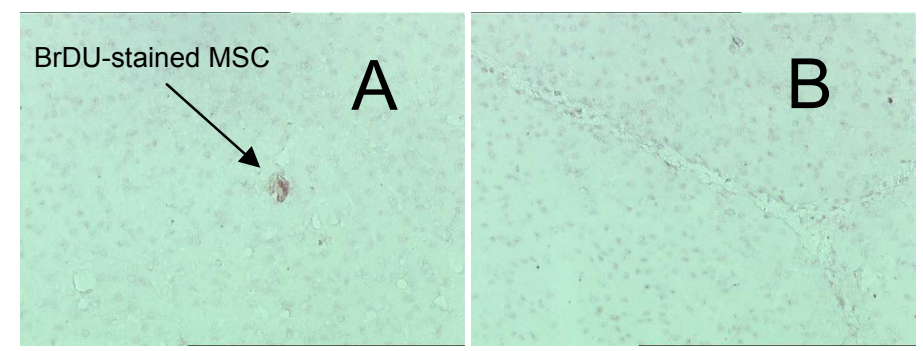

Fig. 12. Identification of infused MSC: Solitary BrdU-stained MSC could be identified in the treatment group on day 14(a). No BrdU-positive cells were identified in control animals (b).

The histological examination of biopsies from liver of TNF- a and control group was burden by the time of collection of specimen, when the proliferative phase of liver regeneration is finished factically. The differences in lobulus length were not statisticaly significant ( $\mathrm{p}-$ value $=0.08$ ), but in the cytokine group there were not only small or normal size lobulus, but also many larger lobulus, which were not present in the control group. The statistical analysis of binucleated hepatocytes did not prove any significant differences in this studied histological parameteres. The length of hepatocytes was not proved also as statistically significant parameter. The proliferative activity in both groups was very decreased (Liska, 2012).

In case of comparison of TGF- $\beta 1$ and control group the differences in length of lobuli were not statistically significant (see figure 13). Statistical analysis also showed no significant

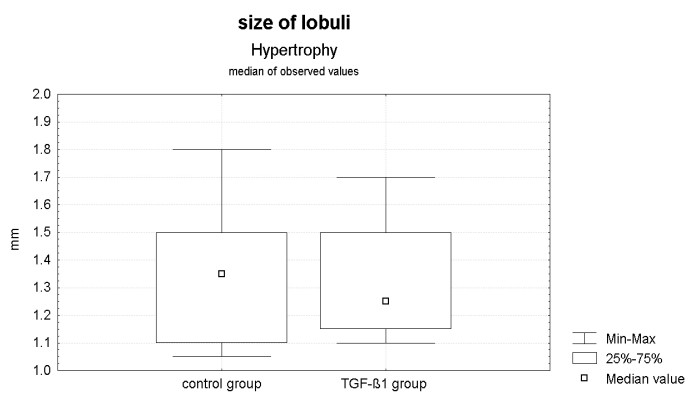

Fig. 13. Comparison of length of lobuli in hypertrophic lobes between TGF- $\beta 1$ and control groups. 
increase in the quantity of binucleated hepatocytes in the hypertrophic liver lobes in the TGF- $\beta 1$ group (see figure 14). We observed a larger distribution of the number of binucleated hepatocytes per field in the hypertrophic lobe from TGF- $\beta 1$ group (1-4 binucleated hepatocytes per field) in contrast to the control group (2-3,5 binucleated hepatocytes per field). The test of normality demonstrated a normal distribution of this parameter in each animal in both experimental groups. The size of hepatocytes was also not proved to be a statistically significant parameter for differences between the TGF- $\beta 1$ group and the control group (see figure 15). Proliferative activity in both groups was greatly reduced.

In case of comparison of histological findings at IL-6 and control groups the differences in lobulus length were not statisticaly significant. The statistical analysis proved significant increased amount of binucleated hepatocytes in hypertrophic liver lobes in IL-6 group (fig. 16). The length of hepatocytes was not proved also as statistically significant parameter. The proliferative activity in both groups was very decreased (Liska, 2009).

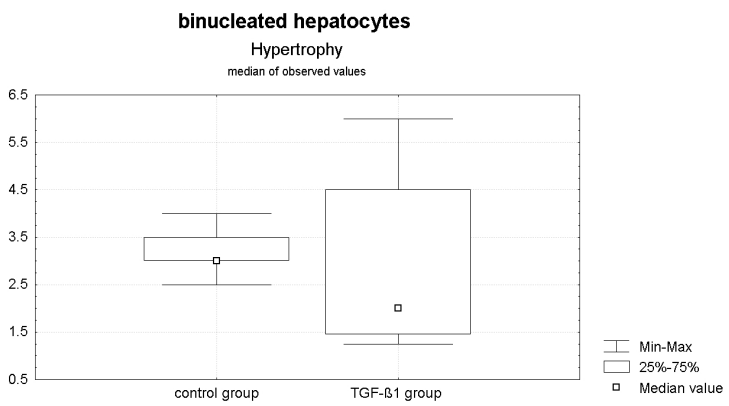

Fig. 14. Comparison of the concentration of binucleated hepatocytes in hypertrophic lobes between TGF- $\beta 1$ and control groups. The binucleated hepatocytes were detected in 20 microscopic fields.

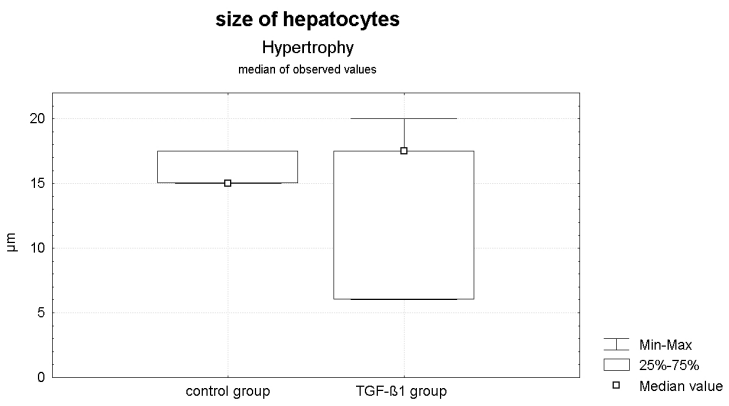

Fig. 15. Comparison of size of hepatocytes in hypertrophic lobes between TGF- $\beta 1$ and control groups. 


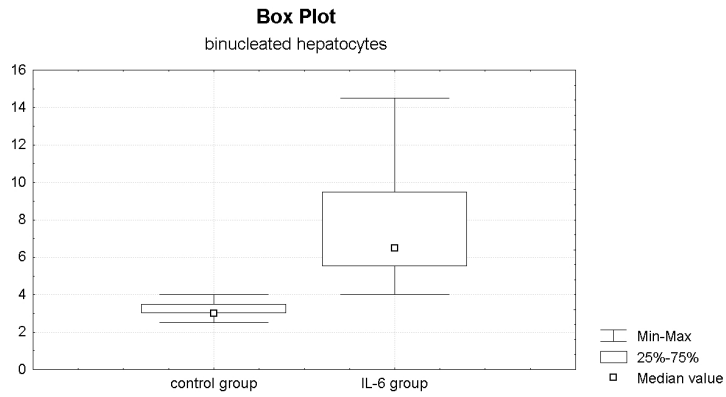

Fig. 16. Comparison of concentration of binucleated hepatocytes in hypertrophic lobes between IL-6 group and control group. The binucleated hepatocyte were detected in 20 microscopical fields.

\section{Discussion}

\subsection{Functional liver remnant volume}

In the presented chapter the authors want to review all experiences with influence of experimental portal vein ligation with cytokines, monoclonal antibody against growth factor and mesenchymal stem cells. This model closely mimics the situation of human oncological liver surgery, in which portal vein embolization can be utilized to create a larger future liver remnant volume before resection. The clinical goal of portal vein embolization is to increase the number of patients that can undergo extensive liver resections. This porcine experimental model of liver regeneration is especially applicable to the clinical situation since pigs closely resemble human liver anatomy and fysiology (Liska, 2009, Liska, 2009).

After portal venous infusion of MSC in this model, augmented and accelerated regeneration of the non-occluded liver lobes is outlined. This effect was strongest between the third and seventh postoperative day and slowly weaned off thereafter. However, there was no overall volume difference of statistical significance between both groups at the end of the observation period. This result might have been expected, though, since the body weight to liver weight ratio is tightly controlled in most species (Liska, 2009).

Previous studies have tried to clarify the potential contribution of MSC to liver regeneration in rodent models. Most of these approaches used toxic models, in which the intrinsic selfrenewing capacity of the recipient liver was suppressed (Dahlke, 2003, Kang, 2005). Di Bonzo observed only $0,2 \%$ human hepatocytes after transplantation of human MSC into immunodeficient mice with chronic liver injury (Di Bonzo, 2008). Overall, whether MSC can significantly contribute to liver regeneration in vivo remains controversial (Dahlke, 2004, Lysy, 2008, Popp, 2006), although MSC can show some features of hepatic differentiation in culture or under immunoprivileged conditions (Najimi, 2007, Ong, 2006). Chamberlain observed differentiation of human MSC into hepatocytes after infusion of MSC into foetal sheep (Chamberlain, 2007) and transplantable hepatocytes were also obtained from heavily growth factor-treated MSC (Banas, 2007, Yamamoto, 2008). Despite the fact that it was not possible to identify transplanted MSC within recipient livers in this model after 14 days, liver hypertrophy was augmented. It is therefore likely that bystander effects of the transplanted 
MSC accelerated regeneration in this model. This effect may be well mediated through paracrine effects of the infused MSC on the microenvironment in the periportal regions, where parenchymal regeneration is initiated. Aldeguer et al. suggested that increased production of IL-6 by bone marrow-derived cells, for example, can stimulate intrinsic liver regeneration (Aldeguer, 2002). In addition to being effective in terms of an accelerated regenerative response, the infusion of syngenic MSC into the portal vein also proved to be safe in the preclinical model. Probable side effects of MSC infusions include immunological problems (hypersensitivity, immune complex reactions), metabolic dysregulation and emboli. None of these problems occured in the presented study cohort (Liska, 2009).

The acceleration of growth of hypertrophic liver lobes after application of TNF-a confirmed results gained at in vitro models and in experiments in small laboratory animals (Cornell, 1990). The selected concentration of applied cytokine initiated acceleration of regeneration of liver parenchyma in non-occluded liver lobes (Heinrich, 2006, Teoh, 2006).

The acceleration of growth of hypertrophic liver lobes after application of IL-6 confirmed results gained at in vitro models and in experiments in small laboratory animals (Cornell,1990, Fukuhara, 2003). The selected concentration of applied cytokine initiated acceleration of regeneration of liver parenchyma in non-occluded liver lobes (Baier,2006, Heinrich, 2006).

We presented possibilities of the application of extrinsic MAB TGF- $\beta 1$ to increase the required future remnant liver volume after partial portal vein ligation. The absolute volume of hypertrophic lobes (left lateral and medial lobes) grew more rapidly after application of MAB TGF- $\beta 1$, whereas the control group had a slow but continual growth in the hypertrophic liver lobes during the whole follow-up period. The augmentation of growth of the hypertrophic lobes was maximal between the $3^{\text {rd }}$ and $7^{\text {th }}$ postoperative days in comparison with the control group $(\mathrm{p}<0.05)$. Nevertheless this growth accelerating effect was lost during the next ultrasonographic controls, and on the $14^{\text {th }}$ postoperative day there were no statistically significant differences. The results of the presented study confirmed in large animal experiment previous findings gained using in vitro models and in experiments with small laboratory animals (Armendariz-Borunda, 1993, Armendariz-Borunda, 1997, Deneme, 2006, Delgado-Rizo, 1998). The selected concentration and timing of the application of monoclonal antibody prolonged acceleration of liver parenchyma regeneration in non-occluded liver lobes of animals (Armendariz-Borunda, 1993, Deneme, 2006). The secondary effects that could be hypothesized after application of the monoclonal antibody against key pleiotropic growth factor (changes in immune reactions and homeostasis) were not observed either during application or in the whole postoperative period. In previous described experimental groups (IL-6 and TNF-a group) we have shown the importance and usefulness of cytokines of the first phase of liver regeneration that increase priming of the hepatocytes - Interleukine- 6 and Tumor necrosis factor - a (Liska, 2009, Liska, 2012), but these cytokines have pleitropic functions, which could be altered or changed by application of these cytokines from an extrinsic source. The choice of the monoclonal antibody against growth factor that terminates this first phase of liver regeneration and stimulates hepatocytes to differentiation, production of extracellular matrix and remodelation of liver tissue structure, imitates the same effect of these named cytokines (Kusaka, 2004).

The present study describes a new usage of a monoclonal antibody against TGF- $\beta 1$ in large animal experimental model of partial portal vein ligation, which simulates the situation in 
human medicine. The achieved acceleration of growth of the hypertrophic liver lobes after application of monoclonal antibody against TGF- $\beta 1$ between $3^{\text {rd }}$ and $7^{\text {th }}$ postoperative days confirmed the key role of the studied cytokine in terminating the regeneration of liver parenchyma after portal vein ligation. The experimental results could be settings for a clinical study in patients with a low response regeneration of future liver remnant volume after portal vein embolization that does not allow surgical treatment (Liska, 2012).

\subsection{Biochemistry}

All biochemical parameters, including cytokine levels, that were assessed during the observation period, did not outline any significant differences between the MSC-infused and the control group, indicating that both groups were systemically stable throughout the regenerative period. Concerning the role of cytokines it may also be assumed that these act on a more local level within the liver parenchym and differences cannot be observed in the periphery (Liska, 2009).

On the contrary application of TNF-a brought the tendency to differences in serum level of AST, ALT, GGT and creatinine in postoperative period, which were not statistically significant. All these biochemical parameters could be due to operative stress and also to occlusion of portal branches of right liver lobes, which represent significant liver function reserves. The postoperative elevation of these parameters could be hypothesized also to atrophic changes in occluded lobes. This reduction of expected increased serum level of discussed biochemical parameters after application of studied cytokine in non occluded portal vein could present also one of its pleiotropic functions - hepatoprotection agains changes after operative stress and reduction of functional parenchyma (Teoh, 2006, Baier, 2006). This hypothesis should be probably examined on non-resection experimental model (Liska, 2012).

We did not prove any statistically significant differences between serum levels of studied biochemical parameters in particular time points between IL-6 and control groups. It demonstrates also no unsuitable influence of applied cytokine on the liver function. The changes in serum levels of studied cytokines, growth factors were also not observed as different between IL-6 and control group in separate time points (Liska, 2009).

In case of comparison of TGF- $\beta 1$ and control group no statistically significant differences were shown between serum levels of the studied biochemical parameters at particular points in time. This also demonstrates that there was no unsuitable influence of the applied monoclonal antibody on the liver function. This results support our ideas to choose monoclonal antibody against TGF- $\beta 1$ for future clinical studies in human liver (Liska, 2012).

\subsection{Histology and immunohistochemistry}

No histological differences were observed after 14 days between the groups (number of mitotic figures, binucleated hepatocytes, length of lobuli, hepatocyte size), indicating that the initial phase of liver regeneration had been completed in both groups and there was no influence of the infused MSC on liver architecture. Using BrdU staining, only very few of the infused MSC could be detected. Thus, injected MSC do not contribute to liver regeneration through proliferation, but most likely help to establish a micormilieu supportive for intrinsic proliferation of resident hepatocytes. Results acquired by this experimental study confirm the experiences of Furst and Esch, who have previously shown that cell grafts of bone marrow 
origin (CD133 positive cells) applied after PVE in human surgery can increase the FLRV (Furst, 2007). From the present experimental data, however, it cannot be concluded with certainty that the application of stem cells, including MSC, does not support the growth of liver malignancies to the same extent that it supports liver regeneration. Assuming a bystander effect of MSC on the micromilieu makes this even more likely (Alison, 2006). Thus, further animal investigation is necessary before optimized MSC therapies can be applied in the setting of human medicine (Alison, 2006). In conclusion, it has been hereby shown that the intraportal infusion of syngeneic porcine MSC after PVE in a setting of liver regeneration led to an accelerated and augmented compensatory liver hypertrophy. This effect is most likely due to bystander effects of the transplanted MSC (Liska, 2009).

The increased number of larger lobulus in the hypertrophic parenchyma of TNF-a group in comparison with control group could be explained by incomplete liver regeneration. Because there are practically no mitotic figures or the amount is of same quantity as in the normal liver parenchyma without any surgical procedures or toxic insult, we could hypothesize, that the first phase of liver regeneration is finished and the next phase of regeneration proceeds. It means the remodelation phase and the phase, when the liver microstructure is restored. Next would be objective to future study - the detection of intracellular or extracelular matrix changes during the process of liver regeneration. No differences in the amount of binucleated hepatocytes could be discussed also by end of proliferative phase of liver parenchyma at the time of sampling. The same size of hepatocytes and no atypical hepatocytes in the biopsies could also be explained by the same reason. This hypothesis is supported by restitution of all liver function monitored by biochemical parametres at the moment of sacrifying of experimental animals (Liska, 2012).

The increased number of binucleated hepatocytes in the hypertrophic parenchyma of IL-6 group in comparison with control group could be explained by incomplete liver regeneration at the end of experiment. Because there are practically no mitotic figures or the amount is of same quantity as in the normal liver parenchyma without any surgical procedures or toxic insult, we could hypothesize, that the first phase of liver regeneration is finished and the next phase of regeneration proceeds. It means the remodelation phase and the phase, when the liver microstructure is restored. Next would be objective to future study - the detection of intracellular or extracellular (matrix) changes during the process of liver regeneration. No significant differences in other histological parameters (diameter of lobulus and hepatocytes) were not proved (Liska, 2009).

The larger distribution of the number of binucleated hepatocytes in the hypertrophic parenchyma of TGF- $\beta 1$ group in comparison with the control group could be explained by incomplete liver regeneration at the end of experiment. Because there are practically no mitotic figures, or the amount is the same as in the normal liver parenchyma without any surgical procedures or toxic insult, it was possible to hypothesize that the first phase of liver regeneration was finished and the next phase of regeneration was proceeding, namely the remodelling phase and the phase when the liver microstructure is restored (Mangnall, 2003). The size of hepatocytes and the length of lobuli were not proved to be statistically different between study and control group. The same size of hepatocytes and length of lobuli in the bioptical samples from the hypertrophic parenchyma could be also explained in the same way. This hypothesis is supported by the restitution of all liver functions monitored by biochemical parameters and completion of the proliferative phase of liver regeneration at the moment of sacrificing of the experimental animals (Liska, 2012). 


\section{Conclusion}

Application of IL-6 and TNF-a augments hypertrophy of FLRV on 7th postoperative day in comparison to control group. In case of application of MAB TGF- $\beta 1$ we observed maximal increase of FLRV between 3rd and 7th days. Application of MSC augments hypetrophy of FLRV on 3rd day. The biochemical and histological examinations did not prove any important differencies among the groups. The use of TNF- $a$, IL-6, MAB TGF- $\beta 1$, MSC could increase the process of liver regeneration after portal vein ligation.These experimental results could be used in clinical practice in patients with risk of acute liver failure after extended liver resection.

\section{Summary}

The aim of presented studies was to influence regeneration of liver parenchyma after portal vein embolization/ligation. Physiological solution (controls, 9 animals) or TNF-a (9) or interleukin-6 (8) or MSC (6) were applied into non-occluded portal vein branches after ligation of portal vein branches for right lobes. Administration of MAB TGF- $\beta 1$ was performed 24 hours after ligation (7). Compensatory hypertrophy (FLRV) was followed-up in next 14 days by regular ultrasonography, serum level of biochemical parametres and by histological examinations. Application of IL-6 and TNF- $\alpha$ augments hypertrophy of FLRV on 7 th postoperative day in comparison to control group. In case of application of MAB TGF- $\beta 1$ we observed maximal increase of FLRV between 3rd and 7th days. Application of MSC augments hypetrophy of FLRV on 3rd day. The biochemical and histological examinations did not prove any differences among the groups. The use of TNF- $\alpha$, IL-6, MAB TGF- $\beta 1$, MSC could increase the process of liver regeneration after portal vein ligation.

Keywords: Liver surgery, Liver regeneration, Experimental study, Porcine model, Experimental model, Portal vein embolization, TNF- $\alpha$, Interleukin-6, Mesenchymal stem cells, TGF- $\beta 1$.

\section{Acknowledgement}

Supported by grants IGA MZ CR 12025 and Research project MSM 0021620819 (Replacement of some vital organs).

\section{References}

Abdalla, E. K., Hicks M. E. \& Vauthey, J. N. (2001). Portal vein embolization: rationale, technique and future prospects. British Journal of Surgery, Vol. 88, No. 7, (July 2001), pp. 165-175, ISSN 1365-2168

Alison, M.R. et al.(2006): Stem cell plasticity and tumour formation. Eur J Cancer, 42, pp 1247-1256. ISSN: 0959-8049

Aldeguer, X. et al. (2002). Interleukin-6 from intrahepatic cells of bone marrow origin is required for normal murine liver regeneration. Hepatology, Vol. 35, No. 1, (January 2002), pp. 40-48, ISSN 1527-3350

Armendariz-Borunda, J. et al. (1993). Transforming growth factor beta gene expression is transiently enhanced at a critical stage during liver regeneration after $\mathrm{CCl} 4$ treatment. Laboratory Investigation, Vol. 69, No. 3, (1993), pp. 283-294, ISSN 0023-6837 
Armendariz-Borunda, J. et al. (1997). Antisense S-oligodeoxynucleotides down-regulate TGFbeta-production by Kupffer cells from CCl4-injured rat livers. Biochimica et Biophysica Acta, Vol. 1353, No. 3, (September 1997), pp. 241-252, ISSN 0006-3002

Azoulay, D. et al. (2000). Resection of non-resectable liver metastases from colorectal cancer after percutaneus portal vein embolization. Annals of Surgery, Vol. 231, No. 4, (April 2000), pp. 480-486, ISSN 0003-4932

Baier, P. K. et al. (2006). Hepatocyte proliferation and apoptosis in rat liver after liver injury. Hepato-Gastroenterology, Vol. 53, No. 71, (September-October 2006), pp. 747-752, ISSN 0172-6390

Banas, A. et al. (2007). Adipose tissue-derived mesenchymal stem cells as a source of human hepatocytes. Hepatology, Vol. 46, No. 1, (July 2007), pp. 219-228, ISSN 1527-3350

Barry, F. P. (2003). Biology and clinical applications of mesenchymal stem cells. Birth Defects Research Part C: Embryo Today, Vol. 69, No. 3, (August 2003), pp. 250-256, ISSN $1542-$ 975X

Broering, D. C. et al. (2002). Portal vein embolization vs. portal vein ligation for induction of hypertrophy of the future liver remnant. Journal of Gastrointestinal Surgery, Vol. 6, No. 6, (November-December 2002), pp. 905-913, ISSN 1091-255X

Bustos, M. et al. (2000). Liver damage using suicide genes: a model for oval cell activation. The American Journal of Pathology, Vol. 157, No. 2, (August 2000), pp. 549-559, ISSN 0002-9440

Chamberlain, J. et al. (2007). Efficient generation of human hepatocytes by the intrahepatic delivery of clonal human mesenchymal stem cells in fetal sheep. Hepatology, Vol. 46, No. 6, (December 2007), pp. 1935-1945, ISSN 0270-9139

Coelho, M. C. et al. (2007). Expression of interleukin 6 and apoptosis-related genes in suckling and weaning rat model of hepatectomy and liver regeneration. Journal of Pediatric Surgery, Vol. 45, No. 4, (April 2007), pp. 613-619, ISSN 0022-3468

Cornell, R. P. (1990). Acute phase responses after acute liver injury by partial hepatectomy in rats as indicators of cytokine release. Hepatology, Vol. 11, No. 6, (June 1990), pp. 923-931, ISSN 0270-9139

Dahlke, M. H. et al. (2004). Stem cell therapy of the liver--fusion or fiction? Liver transplantation, Vol. 10, No. 4, (April 2004), pp. 471-479, ISSN 1527-6465

Dahlke, M. H. et al. (2003). Liver regeneration in a retrorsine/CCl4-induced acute liver failure model: do bone marrow-derived cells contribute? Journal of Hepatology, Vol. 39, No. 3, (September 2003), pp. 365-373, ISSN 0168-8278

Delgado-Rizo, V. et al. (1998). Treatment with anti-transforming growth factor beta antibodies influences an altered pattern of cytokines gene expression in injured rat liver. Biochimica et Biophysica Acta, Vol. 1442, No. 1, (October 1998), pp. 20-27, ISSN 0006-3002

Deneme, M. A. et al. (2006). Single dose of anti-transforming growth factor-beta1 monoclonal antibody enhances liver regeneration after partial hepatectomy in biliary-obstructed rats. The Journal of Surgical Research, Vol. 136, No. 2, (December 2006), pp. 280-287, ISSN 0022-4804

di Bonzo, L. V. et al. (2008). Human mesenchymal stem cells as a two-edged sword in hepatic regenerative medicine: engraftment and hepatocyte differentiation versus profibrogenic potential. Gut, Vol. 57, No. 2, (February 2008), pp. 223-231, ISSN 0017-5749

Duncan, J. R. et al. (1999). Embolization of portal vein branches induces hepatocyte replication in swine: a potential step in gene therapy. Radiology, Vol. 210, No. 2, (February 1999), pp. 467-477, ISSN 0033-8419

Fausto, N. \& Riehle, K. J. (2005). Mechanisms of liver regeneration and their clinical implications. Journal of Hepato-Biliary-Pancreatic Surgery. Vol. 12, No. 3, (2005), pp. 181-189, ISSN 0944-1166 
Fausto, N. (2000). Liver regeneration. Journal of Hepatology. Vol. 32, Suppl. 1, (2000), pp. 1931, ISSN 0168-8278

Friedman, S. L. (2008). Mechanisms of hepatic fibrogenesis. Gastroenterology, 2008, Vol. 134, No. 6, (May 2008), pp. 1655-1669, ISSN 0016-5085

Fukuhara, Y. et al. (2003). Gene expression in the regenerating rat liver after partial hepatectomy. Journal of Hepatology, Vol. 38, No. 6, (June 2003), pp. 784-792, ISSN 0168-8278

Furst, G. Et al. (2007): Portal vein embolization and autologous CD133+ bone marrow stem cells for liver regeneration: initial experience. Radiology, 243, pp 171-179. ISSN 0033-8419

Harada, H. et al. (1998). Fate of human liver after hemihepatic portal vein embolization: cell kinetic and morphometric study. Hepatology, Vol. 26, No. 5, (November 1997), pp. 1162-1170, ISSN 0270-9139

Heinrich, S. et al. (2006). Portal vein ligation and partial hepatectomy differentially influence growth of intrahepatic metastasis and liver regeneration in mice. Journal of Hepatology. 2006, Vol. 45, No. 1, pp. 35-42, ISSN 0168-8278

Jiang, Y. et al. (2002). Pluripotency of mesenchymal stem cells derived from adult marrow. Nature, Vol. 418, No. 6893, pp. 41-49, (July 2002), ISSN 0028-0836

Kang, X. et al. (2005). Rat bone marrow mesenchymal stem cells differentiate into hepatocytes in vitro. World Journal of Gastroenterology, Vol. 11, No. 22, (2005), pp. 3479-3484, ISSN 1007-9327

Kokudo, N. et al. (2001). Proliferative activity of intrahepatic colorectal metastases after preoperative hemihepatic portal vein embolization. Hepatology, Vol. 34, No. 2, (August 2001), pp. 267-272, ISSN 0270-9139

Kusaka, K. et al. (2004). Factors affecting regeneration after portal vein embolization. Hepatogastroenterology, Vol. 51, No. 56, (March-April 2004), pp. 532-535, ISSN 0172-6390

Lagasse, E. et al. (2000). Purified hematopoietic stem cells can differentiate into hepatocytes in vivo. Nature Medicine, Vol. 6, No. 11, (2000), pp. 1229-1234, ISSN 1078-8956

Lilja, H. et al. (1999). Transforming growth factor beta1 helps maintain differentiated functions in mitogen-treated primary rat hepatocyte cultures. Molecular Cell Biology Research Communications, Vol. 1, No. 3, (June 1999), pp. 188-195, ISSN 1522-4724

Liska, V. et al. (2009). Intraportal injection of porcine multipotent mesenchymal stromal cells augments liver regeneration after portal vein embolization. In Vivo, Vol. 23, No. 2, (March-April 2009), pp. 229-236, ISSN 0258-851X

Liska, V. et al. (2009). Interleukin-6 augments activation of liver regeneration in porcine model of partial portal vein ligation. Anticancer Research. Vol. 29, No. 6, (June 2009), pp. 2371-2377, ISSN 0250-7005

Liska, V. et al.(2009) Cytokines and liver regeneration after partial portal vein ligation in porcine experimental model. Bratislavske lekarske listy, Vol. 110, No. 8, (2009), pp. 447-453, ISSN 1336-0345

Liska, V. et al. Tumour Necrosis Factor-Alpha stimulates liver regeneration after parcial portal vein ligation - experimental study on porcine model, Hepatogastroenterology, Vol. 59, No 114, (2012), pp. 125-132, ISSN 0172-6390

Liska V. et al. Inhibition of Transforming Growth Factor Beta-1 augments liver regeneration after partial portal vein ligation in a porcine experimental model. Hepatogastroenterology, Vol. 59, No 113, (2012), pp. 264-271, ISSN 0172-6390

Lysy, P. A. at al. (2008). Persistence of a chimerical phenotype after hepatocyte differentiation of human bone marrow mesenchymal stem cells. Cell Proliferation. Vol. 41, No. 1, (February 2008), pp. 36-58, ISSN 0960-7722 
Makuuchi, M. et al. (1990). Preoperative portal embolization to increase safety of major hepatectomy for hilar bile duct carcinoma: a preliminary report. Surgery, Vol. 107, No. 5, (May 1990), pp. 521-527, ISSN 0039-6060

Makuuchi, M., Takayasu, K. \& Takayama, T. (1984). Preoperative transcatheter embolization of portal venous branch for patient receiving extended lobectomy du to the bile duct carcinoma. Journal of Japanese Society for Clinical Surgery, Vol. 45, No. 1, (1984), pp. 14-20, ISSN 0386-9776

Mangnall, D., Bird, N. C. \& Majeed, A. W. (2003). The molecular physiology of liver regeneration following partial hepatectomy. Liver International, Vol. 23, No. 2, (April 2003), pp. 124-138, ISSN 1478-3223

Michalopoulos, G. K. \& DeFrances, M. C. (1997). Liver regeneration. Science, Vol. 237, No. 5309, (April 1997), pp. 60-66, ISSN 0036-8075

Najimi, M. (2007). Adult-derived human liver mesenchymal-like cells as a potential progenitor reservoir of hepatocytes? Cell Transplantation, Vol. 16, No. 7, (2007), pp. 717-728, ISSN 0963-6897

Oe, S. et al. (2004). Intact signaling by transforming growth factor beta is not required for termination of liver regeneration in mice. Hepatology, Vol. 40, No. 5, (November 2004), pp. 1098-1105, ISSN 0270-9139

Ong, S. Y., Dai, H. \& Leong, K. W. (2006) Hepatic differentiation potential of commercially available human mesenchymal stem cells. Tissue Engineering, Vol. 12, No. 12, (December 2006), pp. 3477-3485, ISSN 1076-3279

Petersen, B. E. (1999). Bone marrow as a potential source of hepatic oval cells. Science, Vol. 284, No. 5417, (May 1999), pp. 1168-1170, ISSN 0036-8075

Popp, F. C. et al. (2006). Therapeutic potential of bone marrow stem cells for liver diseases. Current Stem Cell Research E Therapy, Vol. 1, No. 3, (September 2006), pp. 411-418, ISSN 1574-888X

Ringe, J. et al. (2002). Porcine mesenchymal stem cells. Induction of distinct mesenchymal cell lineages. Cell and Tissue Research, Vol. 307, No. 3, (March 2002), pp. 321-327, ISSN 0302-766X

Stefano, D. et al. (2005). Preoperative percutaneus portal vein embolization: evaluation of adverse events in 188 patients. Radiology, Vol. 234, No. 2, (February 2005), pp. 625630, ISSN 0033-8419

Teoh, N., Field, J. \& Farrell, G. (2006). Interleukin-6 is a key mediator of the hepatoprotective and pro-proliferative effects of ischaemic preconditioning in mice. Journal of Hepatology, Vol. 45, No. 1, (July 2006), pp. 20-27, ISSN 0168-8278

Vassilopoulos, G., Wang, P. R. \& Russell, D. W. (2003). Transplanted bone marrow regenerates liver by cell fusion. Nature, Vol. 422, No. 6934, (April 2003), pp. 901-904, ISSN 0028-0836

Viebahn, C. S. \& Yeoh, G. C. (2008). What fires prometheus? The link between inflammation and regeneration following chronic liver injury. The International Journal of Biochemistry \& Cell Biology, Vol. 40, No. 5, (2008), pp. 855-873, ISSN 1357-2725

Wang, X. et al. (2003). Cell fusion is the principal source of bone-marrow-derived hepatocytes. Nature, Vol. 422, No. 6934, (April 2003), pp. 897-901, ISSN 0028-0836

Yamamoto, Y. et al. (2008). A comparative analysis of the transcriptome and signal pathways in hepatic differentiation of human adipose mesenchymal stem cells. Federation of European Biochemical Societies Journal, Vol. 275, No. 6, (March 2008), pp. 1260-1273, ISSN 1742-464X

Zimmermann, A. (2004). Regulation of liver regeneration. Nephrology Dialysis Transplantation. Vol. 19, Suppl. 4, (2004), pp. iv6-iv10, ISSN 0931-0509 


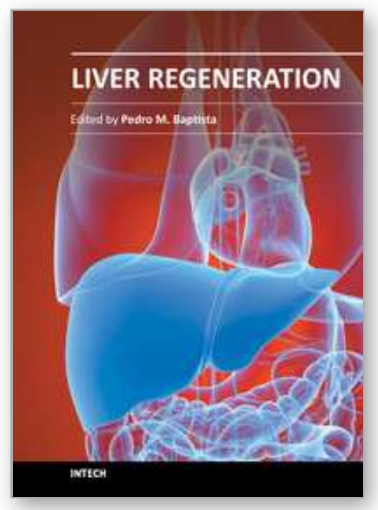

\author{
Liver Regeneration \\ Edited by PhD. Pedro Baptista
}

ISBN 978-953-51-0622-7

Hard cover, 252 pages

Publisher InTech

Published online 16, May, 2012

Published in print edition May, 2012

Doctors and scientists have been aware of the "phenomenom" of liver regeneration since the time of the ancient Greeks, illustrated by the mythic tale of Prometheus' punishment. Nevertheless, true insight into its intricate mechanisms have only become available in the 20th century. Since then, the pathways and mechanisms involved in restoring the liver to its normal function after injury have been resolutely described and characterized, from the hepatic stem/progenitor cell activation and expansion to the more systemic mechanisms involving other tissues and organs like bone-marrow progenitor cell mobilization. This book describes some of the complex mechanisms involved in liver regeneration and provides examples of the most up-to-date strategies used to induce liver regeneration, both in the clinic and in the laboratory. The information presented will hopefully benefit not only professionals in the liver field, but also people in other areas of science (pharmacology, toxicology, etc) that wish to expand their knowledge of the fundamental biology that orchestrates liver injury and regeneration.

\title{
How to reference
}

In order to correctly reference this scholarly work, feel free to copy and paste the following:

Vaclav Liska, Vladislav Treska, Hynek Mirka, Ondrej Vycital, Jan Bruha, Pavel Pitule, Jana Kopalova, Tomas Skalicky, Alan Sutnar, Jan Benes, Jiri Kobr, Alena Chlumska, Jaroslav Racek and Ladislav Trefil (2012). Liver Parenchyma Regeneration in Connection with Extended Surgical Procedure - Experiment on Large Animal, Liver Regeneration, PhD. Pedro Baptista (Ed.), ISBN: 978-953-51-0622-7, InTech, Available from: http://www.intechopen.com/books/liver-regeneration/liver-parenchyma-regeneration-in-connection-withextended-surgical-procedure-experiment-on-large-ani

\section{INTECH}

open science | open minds

\section{InTech Europe}

University Campus STeP Ri

Slavka Krautzeka 83/A

51000 Rijeka, Croatia

Phone: +385 (51) 770447

Fax: +385 (51) 686166

www.intechopen.com

\section{InTech China}

Unit 405, Office Block, Hotel Equatorial Shanghai

No.65, Yan An Road (West), Shanghai, 200040, China

中国上海市延安西路65号上海国际贵都大饭店办公楼 405 单元

Phone: +86-21-62489820

Fax: +86-21-62489821 
(C) 2012 The Author(s). Licensee IntechOpen. This is an open access article distributed under the terms of the Creative Commons Attribution 3.0 License, which permits unrestricted use, distribution, and reproduction in any medium, provided the original work is properly cited. 